\title{
An evaluation of cholesterol determinations in serum and serum lipoprotein fractions by a semi-automated fluorimetric method
}

\author{
GILL ROBERTSON AND D. G. CRAMP \\ From Alexander Simpson Laboratory for Metabolic Research, St Mary's Hospital Medical School, \\ London
}

SYNOPSIS A sensitive automated fluorimetric method for the estimation of cholesterol is described which is suitable for the routine determination of both serum and serum lipoprotein cholesterol. Analyses can be performed at 60 /hour in the serum range of $5 \mathrm{mg}$ to $400 \mathrm{mg} / 100 \mathrm{ml}$. The method shows a high degree of analytical precision and good yields from recovery experiments.

We describe a cholesterol method which involves the measurement of the stable fluorescent product of a Liebermann-Burchard reaction: the cholesterol extract mixed with trichloroethane, acetic anhydride, and concentrated sulphuric acid is excited at $546 \mathrm{~m} \mu$ and fluoresces at $590 \mathrm{~m} \mu$. Originally described by Albers and Lowry (1955), the method was modified by McDougall and Farmer (1957) and Carpenter, Gotsis, and Hegsted (1957). Carpenter's method was subsequently automated by Antonis (1964). The automated technique does not appear to have been evaluated either for measuring serum or the lipoprotein fraction cholesterol.

This paper describes modifications of the automated method and evaluates the measurement of cholesterol in serum and serum lipoprotein fractions. Cholesterol concentrations in the range $5 \mathrm{mg}-150 \mathrm{mg} / 100 \mathrm{ml}$ in lipoprotein fractions and up to $400 \mathrm{mg} / 100 \mathrm{ml}$ in serum may be measured under similar analytical conditions, at a sampling rate of 60 per hour.

\section{Materials and Method}

\section{REAGENT}

The reagent is made immediately before use by mixing $400 \mathrm{ml}$ of redistilled 1, 1, 2-trichloroethane $^{1}$ and $80 \mathrm{ml}$ of analytical reagent grade

${ }^{1}$ Kodak, Ltd, Kirkby, Liverpool.

Received for publication 26 June, 1969. acetic anhydride, cooling the mixture to $-15^{\circ} \mathrm{C}$ and then adding $20 \mathrm{ml}$ of concentrated sulphuric acid.

ST ANDARDS

Working cholesterol standards in the range of $20 \mathrm{mg} / 100 \mathrm{ml}$ to $400 \mathrm{mg} / 100 \mathrm{ml}$ are prepared in analytical grade chloroform and extracted as described for serum according to Bragdon (1960).

\section{SAMPLE PREPARATION}

\section{Serum}

One millilitre of serum is extracted into $24 \mathrm{ml}$ of a 2:1 chloroform-methanol mixture (Bragdon, 1960). The extraction mixture is washed with $0 \cdot 1 \mathrm{~N}$ sulphuric acid. The lower chloroform layer of the resultant two-phase system contains all the lipid in $16 \mathrm{ml}$ and is used for analysis.

\section{Separation of lipoprotein fractions}

Very low density (Sf 12-400), low density (Sf 0-12). and high density lipoproteins are separated sequentially from chylomicron-free serum in a Beckman preparative ultracentrifuge in gradeddensity salt solutions, by a method essentially that of Havel, Eder, and Bragdon (1955).

Three millilitres of each fraction is extracted into chloroform-methanol as already described. 
Sampler 2: 60/hr: cam 1:2

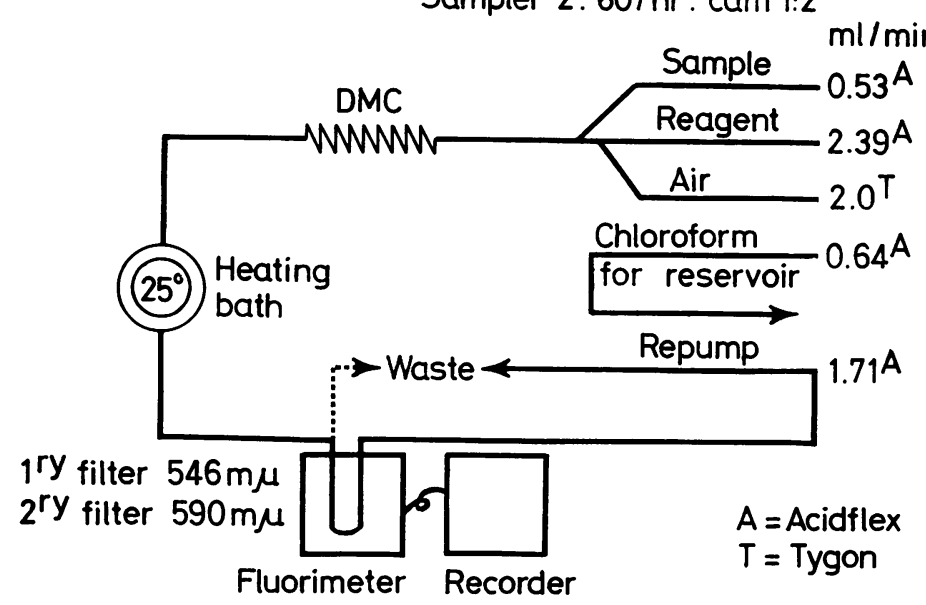

Fig. 1 Manifold and flow diagram.

\section{Automated procedure}

The automated system consists of a Technicon AutoAnalyzer sampler II and proportioning pump; a $25^{\circ} \mathrm{C}$ heating bath containing a $40 \mathrm{ft}$ delay coil, a Locarte filter fluorimeter fitted with a flow cell, and, a $10 \mathrm{mV}$ potentiometric recorder (Fig. 1). The primary filters activate at $546 \mathrm{~m} \mu$ (Corning filters 4010 and 5120) and emission is measured at $590 \mathrm{~m} \mu$ (Corning filter 2424). Glass sample cups are used. Results are interpreted from a standard curve which is linear up to 400 $\mathrm{mg} / 100 \mathrm{ml}$ and corrections are made for the dilutions involved. Commercially prepared control sera ${ }^{1,2}$ are included in each batch of analyses.

\section{Results}

A straight-line relationship is obtained with standard cholesterol in the range $20-400 \mathrm{mg} / 100$ $\mathrm{ml}$; a chart record showing a duplicated standard curve and typical sample peaks is shown in Figure 2.

This method shows a high degree of reproducibility and precision and a satisfactory degree of correlation was obtained in a comparison with the manual method previously used in this laboratory (Henley, 1957); 116 serum samples were analysed and compared with results obtained on the same samples by the manual method of Henley (1957). The distribution and correlation coefficient ( $r$ ) are shown in Fig. 3, where $r=0.980 \quad(P<0.001)$. The respective mean values obtained by the manual and automated methods were $186 \mathrm{mg}$ and 182 $\mathrm{mg} / 100 \mathrm{ml}$. There was no significant difference between the results from the two methods at any level. The within-method variance was the

Fig. 2 Recording of (a) standard curve, (b) duplicate standards and (c) replicate samples.
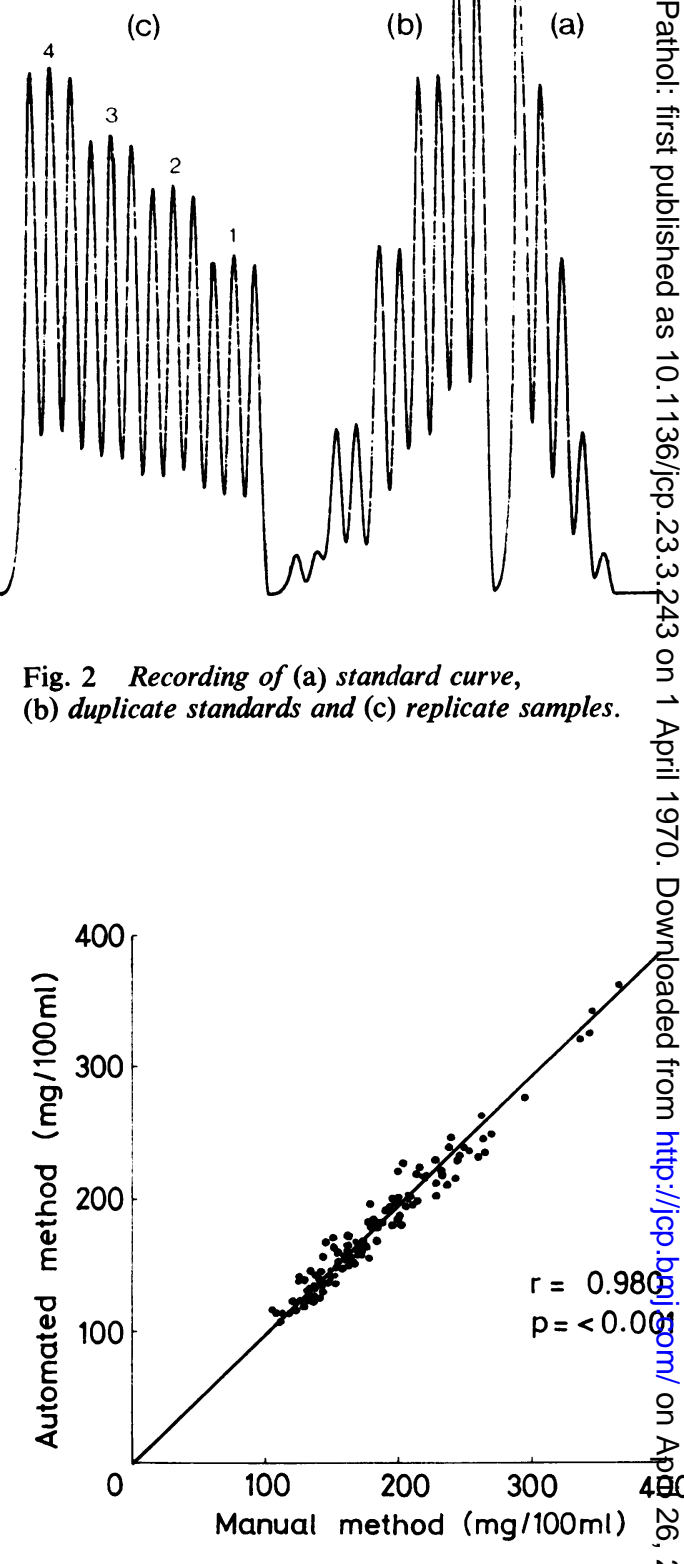

Fig. 3 Correlation between manual and automated method.

same as the variance between them as calculated by the $F$ test. The standard error of the mean of replicated samples was $\mathbf{0 \cdot 6}$. Recovery of added cholesterol from serum averaged $97 \%$ (93 $\overrightarrow{\text { के }}$ $99 \%$ ) over the range 40 to $370 \mathrm{mg} / 100 \mathrm{ml}$.

Total cholesterol and lipoprotein fraction cholesterol were measured on 29 serum samples. The results in $\mathrm{mg} / 100 \mathrm{ml}$ and the percentage recoveries (Table) show good agreement between total serum cholesterol and the sum of tie individual fractions. 


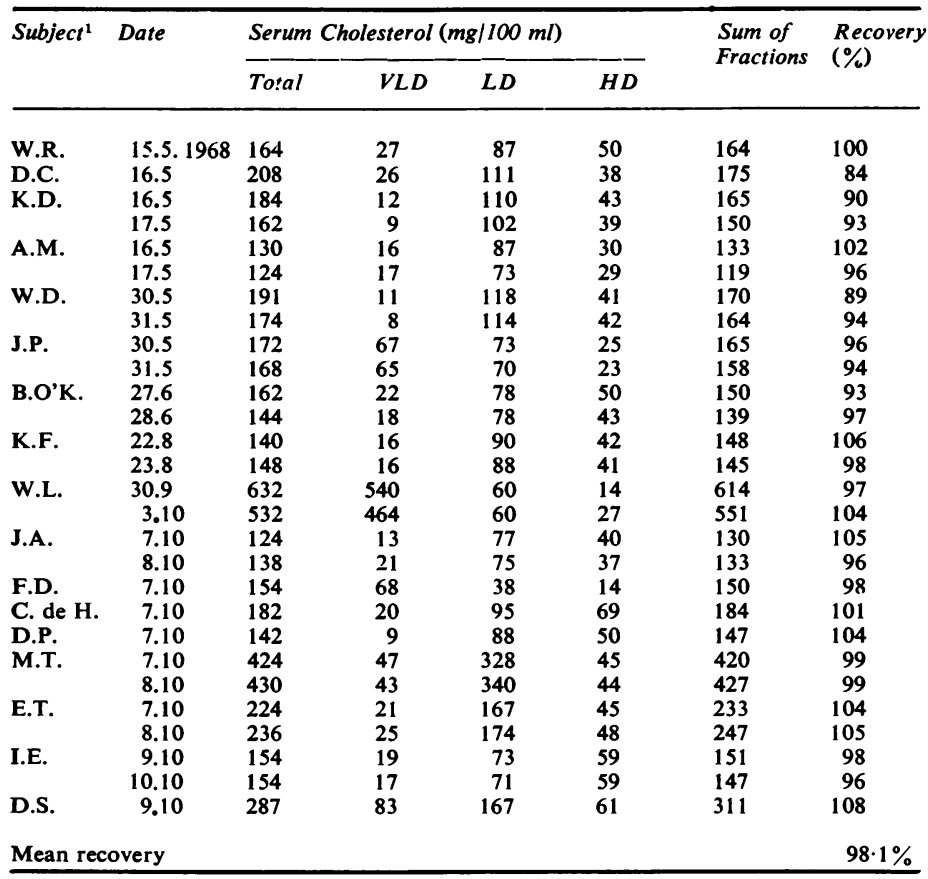

Table Serum cholesterol and serum lipoprotein fractions

${ }^{1}$ VLD, LD, HD = very low, low and high density lipoprotein respectively

\section{Discussion}

Current interest in atherosclerosis and the lipaemias has heightened the demand for precise measurement not only of serum cholesterol, but also for measurement of the cholesterol, triglyceride, and phospholipid fractions that comprise the lipid moiety of the lipoproteins.

This cholesterol method provides a high degree of sensitivity essential for accurate measurement of low cholesterol concentrations and is fairly specific. For, although under the conditions of this assay a mixture of products is formed, evidence for which is shown by the intense emission of blue fluorescence when excited with $365 \mathrm{~m} \mu$ light, in fact, activation at $546 \mathrm{~m} \mu$ and measurement of the red-orange fluorescence $(590 \mathrm{~m} \mu)$ gives high specificity for cholesterol (Albers and Lowry, 1955). With the automated system described and using a sampler II, a back reservoir is not required, and there is an effective gain in sampling rate, 60 an hour compared with 30 an hour. The 1 : 2 sample-to-wash ratio provides a good wash pattern without carry-over, which increases the sensitivity in the lipoprotein fraction assays and also diminishes the sample volume required.

Chloroform is chosen as the extracting medium for several reasons. The sample extract can be used directly for analysis without prior need to dry extracts and reconstitute the residues in trichloroethane. It was found, in fact, that $c$ results were more reproducible when using chloro- $C$ form extracts in the reaction than when trichloro- $\bar{J}$ ethane extracts were prepared, though care must be taken to prevent evaporation from a considerably lower boiling-point solvent.

The bromide ions in the mixed salt solutions in which the lipoprotein fractions are suspended cause considerable interference in the automated colorimetric procedure (Technicon Instrument Co., Methodology sheet no. 24). In that procedure a polar solvent extract (iso-propanol) is used from which both the lipids and the salt ions are extracted. The fluorimetric method described is particularly advantageous in being an almost totally non-aqueous system, and halide ions are eliminated at the initial extraction step.

It is important to extract the standard solutions in a similar manner to the serum samples, since the very small mutual solubility of chloroform and water alters the slope of the standard curve by about $10 \%$.

Inherent advantages of this method are the simplified manifold and the increased rate of analysis. Our results confirm that the method is suitable for the routine analysis of serum cholesterol and the cholesterol of serum lipoprotein fractions. It matches in sensitivity the semi-automated method used for measuring glyceride-glycerol described previously from this laboratory (Cramp and Robertson, 1968).

This work has has been supported bv contract no. Ph-43-67-1344 of the US National Institutes of Health. We wish to thank Professor V. Wynn for providing facilities and opportunity to carry out this work.

\section{References}

Albers, R. W., and Lowry, O. H. (1955). Fluorometric determination of 0.1 to 10 micrograms of cholesterol. Analyt. Chem., 27, 1829-1831.

Antonis, A. (1964). Automated Techniques in Serum Lipid Analysis. Technicon Instrument Co, Chauncey, New York.

Bragdon, J. H. (1960). Extraction of lipids from serum. In Lipids and the Steroid Hormones in Clinical Medicine. Edited by F. W. Sunderman and F. W. Sunderman Jr., pp. 6-8. Lippincott, Philadelphia.

Carpenter, K. J., Gotsis, A., and Hegsted, D. M. (1957). Estimation of total cholesterol in serum by a micro method. Clin. Chem., 3, 233-238.

Cramp, D. G., and Robertson, G. (1968). The fluorimetric assay of triglyceride by a semiautomated method. Analyt. Biochem., 25, 246-251.

Havel, R. J., Elder, H. A., and Bragdon, J. H. (1955). The distribution and chemical composition of ultra centrifugally separated lipoproteins in human serum. J. clin. Invest., 34, 1345-1353.

Henley, A. A. (1957). The determination of serum cholesterol. Analyt, 82, 286-287.

McDougal, D. B., Jr., and Farmer, H. S. (1957). A fluorometric method for total serum cholesterol. J. Lab. clin. Med. $50,485-488$.

Technicon Instrument Co, Methodology Sheet no. 24. Chauncey, New York. 